\title{
Low-Cost Customized Cranioplasty with Polymethyl Methacrylate Using 3D Printer Generated Mold: An Institutional Experience and Review of Literature
}

\author{
Ankit Chaudhary ${ }^{1}$ Virendra Deo Sinha ${ }^{1}$ Sanjeev Chopra ${ }^{1} \quad$ Jitendra Shekhawat ${ }^{1}$ Gaurav Jain ${ }^{1}$ \\ ${ }^{1}$ Department of Neurosurgery, Sawai Man Singh Medical College, \\ Address for correspondence Virendra Deo Sinha, MS, Mch, \\ Jaipur, Rajasthan, India \\ Department of Neurosurgery, Sawai Man Singh Medical College, \\ Jaipur 302004, Rajasthan, India (e-mail: sinhavd@yahoo.com).
}

Indian J Neurotrauma:2020;17:104-109

\begin{abstract}
Keywords

- contour

- cranioplasty

- customized

- mold

- resin

Background Cranioplasty is performed to repair skull defects and to restore normal skull anatomy. Optimal reconstruction remains a topic of debate. Autologous bone flap is the standard option but it may not be available due to traumatic bone fractures, bone infection, and resorption. The authors present their experience with prefabrication of precise and low-cost polymethyl methacrylate (PMMA) mold using threedimensional (3D) digital printing.

Methods A total of 30 patients underwent cranioplasty between March 2017 and September 2019 at Sawai Man Singh Medical College Jaipur, India. Preoperative data included diagnosis for which decompressive craniectomy was done and Glasgow coma scale score was observed. Intraoperative data included operating time. Postoperative data included cosmetic outcome in the form of cranial contour and margins, complications such as infection, seroma, implant failure, wound dehiscence, and hematoma.

Results Patient age at cranioplasty ranged from 12 to 63 years with a mean age of 36.7 years. The mean operating time was 151.6 minutes (range 130-190 minutes). The mean follow-up period was 8 months (range 6-13 months). Postoperative wound dehiscence developed in one case (3.3\%). Cranial contour and approximation of the margins were excellent and aesthetic appearance improved in all patients.

Conclusion Low-cost PMMA implant made by digital 3D printer mold is associated with reconstruction of the deformed skull contour giving satisfactory results to the patient and his family members, at a low cost compared with other commercially available implants. This technique could be a breakthrough in cranioplasty.
\end{abstract}

\section{Introduction}

The absence of a body part has a great influence on a person's physical and mental state; it causes social interaction difficulty, which frequently limits their hope of recovery. ${ }^{1}$

Decompressive craniectomy is routinely employed not only in the context of traumatic brain injury and stroke, but also more recently following subarachnoid hemorrhage, venous infarction due to dural sinus thrombosis, and osteomyelitis of skull bones. ${ }^{2}$ Atmospheric pressure on the defect has a direct effect on cranium causing headache, confusion, irritability, contralateral weight sensations, and epilepsy. ${ }^{3}$ Osseous cranial defects cause aesthetic abnormalities such as herniation or depression that may severely affect the patients' quality of life. ${ }^{4}$ Repair of cranial defects mainly aims to protect underlying brain tissue, decrease pain at the site of defect, improve appearance, and decrease patients' anxiety ${ }^{5}$ that can be obtained through a multidisciplinary approach with placement of a prosthesis. ${ }^{6-8}$ The various implant materials that are in use today are either autografts or allografts. ${ }^{9,10}$ Autologous bone flap is widely used for cranioplasty as it is relatively inexpensive, easy to obtain, exhibits good fit and
DOI https://doi.org/

10.1055/s-0040-1713459

ISSN 0973-0508.
(C)2020 Neurotrauma Society of India
License terms

(ㅇ)( $\Theta \circledast$ 
contour, presents no risk of disease transmission, and is viable. In many clinical situations, autologous bone flap may be unavailable as in infection and bone resorption when kept in abdomen and bone fragmentation and discontinuation of institutional bone bank due to increasing storage cost.11-14

Cranioplasties with alloplastic materials like methyl methacrylate was done for the first time in 1941 by Kleinschmidt; since then many other alternatives such as titanium, hydroxyapatite (HA), and polyetheretherketone (PEEK) have been used. The ideal material is biocompatible, radiolucent, nontoxic, noncarcinogenic, and easy to use in the operating room; can be used to create an optimal patient-specific implant; brings excellent cosmetic result ability to withstand strain and tension; has the capacity to be sterilized; and is low in cost. ${ }^{9}$ Titanium prosthesis is expensive, has a problem of thermal conduction, and intraoperative modifications cannot be performed. High cost becomes the major limitation in developing countries. On the other hand, polymethyl methacrylate (PMMA) has low cost, and is lightweight, strong, inert, nonferromagnetic, noncarcinogenic, and stable. Disadvantages include low adherence to the surrounding tissue, seroma formation, and it may be bulky in some areas like the orbital rim. Free-hand PMMA prostheses formation, without any mold has certain disadvantages such as, preparation of the mixture in direct contact with the dura mater can produce exothermal reactions during surgery. ${ }^{10}$ Polymerization process generates potentially harmful monomers which can enter the systemic circulation through exposed blood vessels, can cause systemic hypotension, death, and increase the operative time as it requires meticulous implant adjustment for osseous adaptation. Intraoperative implant adjustments may cause poor aesthetic results in large and complex defect. ${ }^{12} 3 \mathrm{D}$ printer-generated mold with PMMA casting over it results in a favorable cosmetic outcome and reduction in operating time necessary for implant placement.

\section{Materials and Methods}

A total number of 30 patients who underwent customized cranioplasty between March 2017 and September 2019 at Sawai Man Singh Medical College Jaipur, India, using 3D printed mold with PMMA casting over it, were studied prospectively. Approval from Institutional review board and consent from the patients or caregivers for photographs were obtained prior to the initiation of the study.

Patients were evaluated with multislice helical computed tomography (CT) scan with slice thickness of $0.8 \mathrm{~mm}$. Digital imaging and communications in medicine (DICOM) data were processed and converted to 3D images with MIMICS 13.1 software (Interactive Medical Image Control System; Materialise Inc., Leuven, Belgium) ( - Fig. 1).

Image of implant mold was generated by a digital subtraction mirror-imaging process whereby the normal side of the cranium was used as a model. Smoothing technique by the MIMICS 13.1 software was used to process stair-like surface of the 3D-implant model. The pre- and postcraniectomy CT

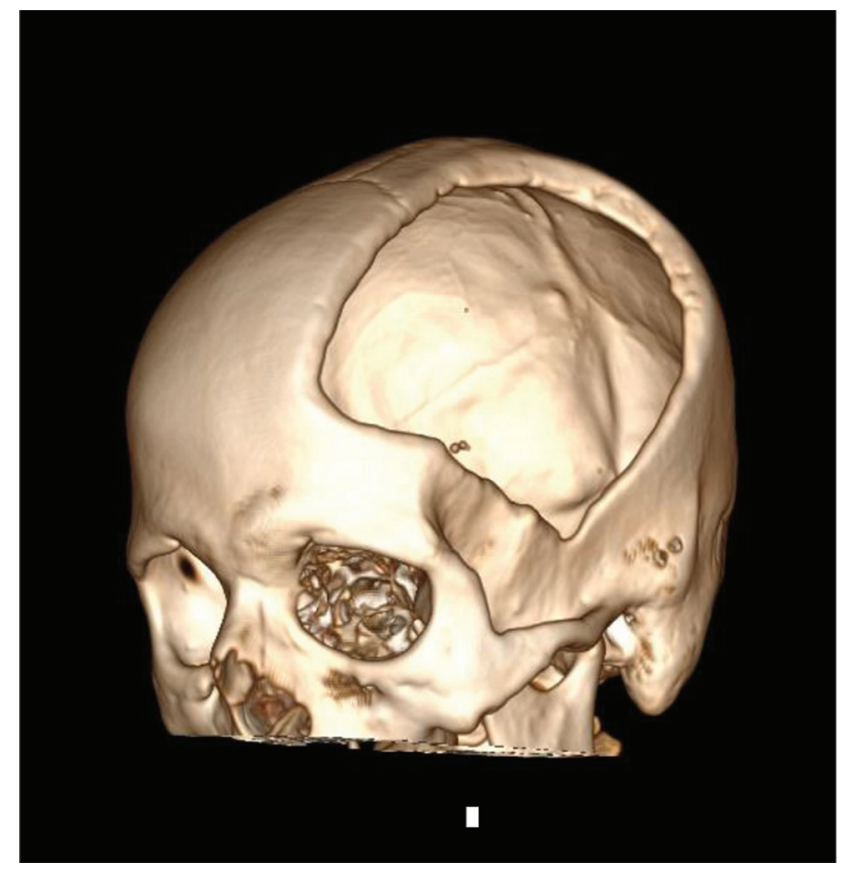

Fig. 1 Three-dimensional (3D) CT reconstructed image of a 26-yearold man with left FTP craniectomy defect.

images were merged, and the 3D implant images were then cropped. Prefabrication of the mold was performed by fused depositional modeling of the poly lactic acid (PLA) beeds. The design process typically lasts between 4 and 5 hours, and the 3D mold printing lasts on an average 10 hour and the mold is then plasma sterilized.

Under GA, after aseptic draping, all the patients were re-explored. Scalp tissue was carefully dissected, and temporalis muscle was sharply dissected of the duramater to expose the sphenoidal edge of the skull defect. The PMMA implant was constructed using the prefabricated mold during the dissection procedure. To prevent adhesion between the implant and the mold, surface of the mold was covered with bone wax or may be even saline was used. The PMMA resin was prepared by mixing polymer powder with a liquid monomer. PMMA resin was evenly distributed onto inner half of the prefabricated mold and then compressed with the external half. Minor trimming around the margins with the microdrill was done so as to achieve exact fit into the defect. The PMMA implant was fixed to the defective region with titanium self-tapping screws. CT scan with 3D reconstruction was done post operatively to look for implant contour and margin apposition (-Fig. 2).

\section{Results}

There were 23 male and 7 female patients. Mean age at the time of cranioplasty was 36.7 years (range 12-63 years). Mean time to cranioplasty following craniectomy was 7.4 months (range 5-13 months). Skull defects were caused by head trauma in 29 patients (96.7\%), while in one patient it was due to postoperative right cerebral infarction caused by right internal carotid artery injury (3.33\%). Unilateral skull 

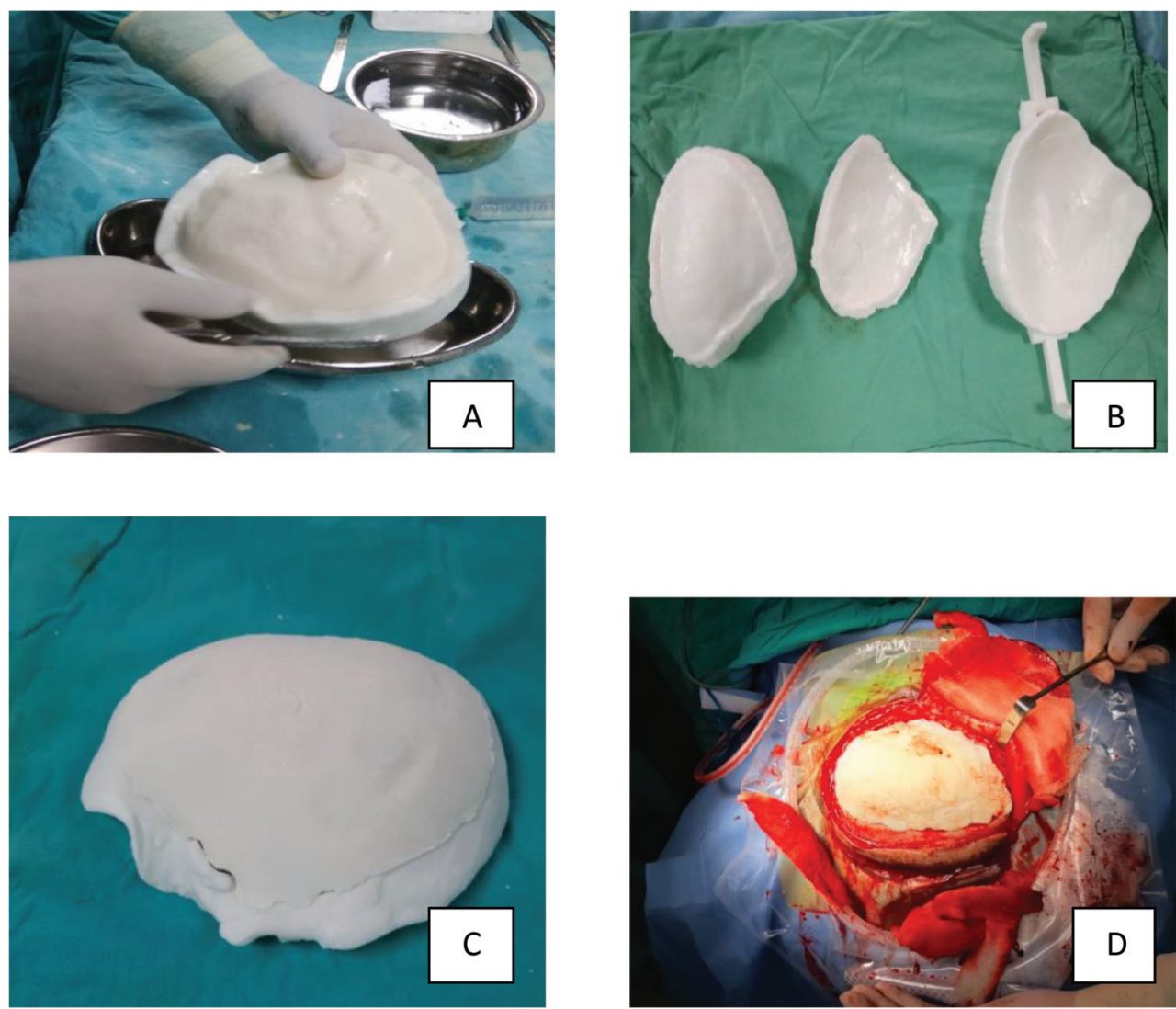

Fig. 2 Polymethyl methylacrylate (PMMA) resin even spread over inner half of the mold (A). PMMA implant shown in the center with the inner and outer half of the mold (B). PMMA customized prosthesis assembled over cranial defect printout to ensure exact margin apposition (C). Placement of PMMA customized prosthesis over the cranial defect intraoperatively (D).

defect was present in 28 patients, 1 patient had bilateral skull defect and 1 patient had midline frontal bone defect. Skull defects were present in frontotemporoparietal region except frontal region in one case. Preoperative assessment revealed $21(70.0 \%)$ patients had Glasgow coma scale (GCS) score 15, 7 (23.3\%) patient had GCS 8 to 14 , and 2 (6.67\%) patients had GCS 3 to 7 . The mean operating time was 151.6 minutes (range 130-190 minutes).

The mean follow-up period was 8 months (range 6-13 months). Postoperative clinical assessment revealed 21 (70.0\%) patients had GCS score 15, 8 (26.7\%) patient had GCS 8 to 14 , and 1 (3.3\%) patients had GCS 3 to 7. - Table 1 below shows baseline characteristic of the patients.

\section{Cosmetic Outcome}

Postoperative CT scans showed excellent restoration of the bony contour and margin ( - Fig. 3 ). Two of our patients had uneven surface of the PMMA implant. We attribute this to insufficient quantity of PMMA resin used for implant formation.

\section{Complications}

Of the 30 patients in our study, 4 (13.3\%) patients developed complications. One patient developed ipsilateral frontal and parietal contusion which was managed conservatively and did not show any deterioration of GCS. One patient operated for bilateral cranioplasty developed extradural hematoma in postoperative CT scan which was managed conservatively with uneventful course. The same patient developed wound dehiscence with pus discharge and implant exposure on right side that required implant removal after one year of surgery. Two patients developed uneven margins due to improper use of resin.

\section{Discussion}

Cranioplasty has a fascinating and ancient history dating back to $7,000 \mathrm{BC}$ according to the archeological evidence. ${ }^{15}$ Civilizations practiced cranioplasty included the Britons, the Asiatics, the Polynesians, and the North Africans. The first documented description of cranioplasty came from Fallopius in the 16th century who proposed that bone could be replaced in cranial fractures provided that the dura was not damaged; if the dura were damaged, the bone would be replaced with a gold plate. ${ }^{16}$ Xenograft used as bone graft was first performed by van Meekeren in $1668 .{ }^{17}$ Later, bone grafts from the rabbit, calf, goose, dog, ape, and eagle have been transplanted into humans. First autologous bone graft cranioplasty was performed by Walther in $1821 .{ }^{17}$ Many bone harvest sites were experimented including the ribs, sternum, scapula, and ilium. ${ }^{15}$ Muller Konig popularized cranium for autologous bone graft by swinging flaps of adjacent tissue that included the skin, periosteum, and the outer table. ${ }^{16}$ Replacement of the original bone removed during craniectomy is 
Table 1 Clinical summary of patients

\begin{tabular}{|c|c|c|c|c|c|c|c|c|}
\hline $\begin{array}{l}\text { Case } \\
\text { no. }\end{array}$ & $\begin{array}{l}\text { Age } \\
(y) / \text { Sex }\end{array}$ & Diagnosis & Location & Side & $\begin{array}{l}\text { Preop } \\
\text { GCS }\end{array}$ & $\begin{array}{l}\text { Postop } \\
\text { GCS }\end{array}$ & $\begin{array}{l}\text { Operation } \\
\text { time } \\
(\min )\end{array}$ & Complication \\
\hline 1 & $25 / M$ & $\mathrm{TBI}$ & FTP & Right & 15 & 15 & 130 & None \\
\hline 2 & $35 / M$ & $\mathrm{TBI}$ & FTP & Right & 15 & 15 & 145 & $\begin{array}{l}\text { Postop CT s/o frontal and parietal } \\
\text { contusion }\end{array}$ \\
\hline 3 & $55 / \mathrm{M}$ & $\mathrm{TBI}$ & FTP & Left & 15 & 15 & 155 & Uneven contour \\
\hline 4 & $25 / F$ & $\mathrm{TBI}$ & FTP & Left & 7 & 10 & 180 & None \\
\hline 5 & $24 / \mathrm{M}$ & $\mathrm{TBI}$ & FTP & Left & 15 & 15 & 135 & None \\
\hline 6 & $23 / \mathrm{M}$ & $\mathrm{TBI}$ & FTP & Left & 15 & 15 & 190 & None \\
\hline 7 & $32 / \mathrm{M}$ & $\mathrm{TBI}$ & FT & Bilateral & 15 & 15 & 170 & $\begin{array}{l}\text { Postop CT s/o B/L ED hematoma, } \\
\text { infection with Wound dehiscence } \\
\text { at } 13 \text { months }\end{array}$ \\
\hline 8 & $26 / \mathrm{M}$ & $\mathrm{TBI}$ & FTP & Right & 15 & 15 & 165 & None \\
\hline 9 & $34 / \mathrm{M}$ & $\mathrm{TBI}$ & FTP & Left & 15 & 15 & 145 & None \\
\hline 10 & $26 / M$ & $\mathrm{TBI}$ & FTP & Left & 15 & 15 & 150 & None \\
\hline 11 & $24 / M$ & TBI & FTP & Left & 15 & 15 & 155 & None \\
\hline 12 & $13 / \mathrm{M}$ & Infarction & FTP & Right & 11 & 12 & 140 & None \\
\hline 13 & $28 / \mathrm{M}$ & $\mathrm{TBI}$ & FTP & Right & 15 & 15 & 160 & None \\
\hline 14 & $21 / \mathrm{M}$ & $\mathrm{TBI}$ & FTP & Right & 15 & 15 & 165 & Uneven contour \\
\hline 15 & $50 / \mathrm{F}$ & $\mathrm{TBI}$ & FTP & Left & 15 & 15 & 130 & None \\
\hline 16 & $24 / M$ & TBI & FTP & Right & 3 & 4 & 135 & None \\
\hline 17 & $35 / F$ & $\mathrm{TBI}$ & FTP & Left & 8 & 8 & 165 & None \\
\hline 18 & $45 / F$ & $\mathrm{TBI}$ & FTP & Right & 15 & 15 & 152 & None \\
\hline 19 & $38 / \mathrm{M}$ & $\mathrm{TBI}$ & Frontal & $R>L$ & 15 & 15 & 140 & None \\
\hline 20 & $12 / \mathrm{M}$ & $\mathrm{TBI}$ & FP & Left & 15 & 15 & 144 & None \\
\hline 21 & $38 / \mathrm{M}$ & TBI & FTP & Right & 13 & 13 & 155 & None \\
\hline 22 & $52 / \mathrm{M}$ & TBI & FTP & Left & 15 & 15 & 142 & None \\
\hline 23 & $45 / F$ & $\mathrm{TBI}$ & FTP & Right & 9 & 9 & 151 & None \\
\hline 24 & $52 / \mathrm{M}$ & $\mathrm{TBI}$ & FTP & Left & 13 & 13 & 138 & None \\
\hline 25 & $59 / \mathrm{M}$ & $\mathrm{TBI}$ & FTP & Right & 11 & 11 & 152 & None \\
\hline 26 & $39 / \mathrm{M}$ & $\mathrm{TBI}$ & FTP & Left & 15 & 15 & 148 & None \\
\hline 27 & $48 / \mathrm{F}$ & TBI & FTP & Left & 10 & 10 & 158 & None \\
\hline 28 & $52 / \mathrm{M}$ & TBI & FTP & Right & 15 & 15 & 150 & None \\
\hline 29 & $63 / \mathrm{M}$ & TBI & FTP & Left & 15 & 15 & 156 & None \\
\hline 30 & $58 / F$ & TBI & FTP & Left & 15 & 15 & 148 & None \\
\hline
\end{tabular}

Abbreviations: DOA, date of admission; ED, extradural; F, female; FTP, frontal temporal parietal; GCS, Glasgow coma scale; M, male; TBI, traumatic brain injury.

preferred as no other graft or foreign materials are introduced. However, autologous bone grafts have certain disadvantages such as bone flap resorption and increased chances of infection as demonstrated by Matsuno et al, compared with PMMA, alumina ceramics, and titanium mesh. ${ }^{18}$ PMMA casting-based alloplastic cranioplasty has become a routine practice to restore part of lost skull vault ${ }^{19}$ as it is highly biocompatible, has relatively low cost, and strong consistency. Free-hand intraoperative molding of the PMMA resin upon the skull defect during its polymerization phase may lead to poor aesthetic outcome as it may be difficult to match with the irregular margins. It also induces an exothermic reaction when it is done directly upon the defective skull vault which can damage sensitive dural and subdural structures. ${ }^{10,20}$ Prefabrication of PMMA implant outside the operative field as in our study with 3D printed mold has the advantage to prevent such complications. Fabrication of craniofacial models can be done by conventional milling techniques, laser stereolithography, and 3D printing technology. ${ }^{21,22}$ In 1990, the construction of biomodels using 4-axis computer numerical control milling techniques was first reported. These biomodels were then used as templates for implants or as a master tool for making molds for the fabrication of implant. ${ }^{23}$ The major disadvantage of the conventional milling technique was not being able to accurately represent the complex anatomy or the inner structure of the 

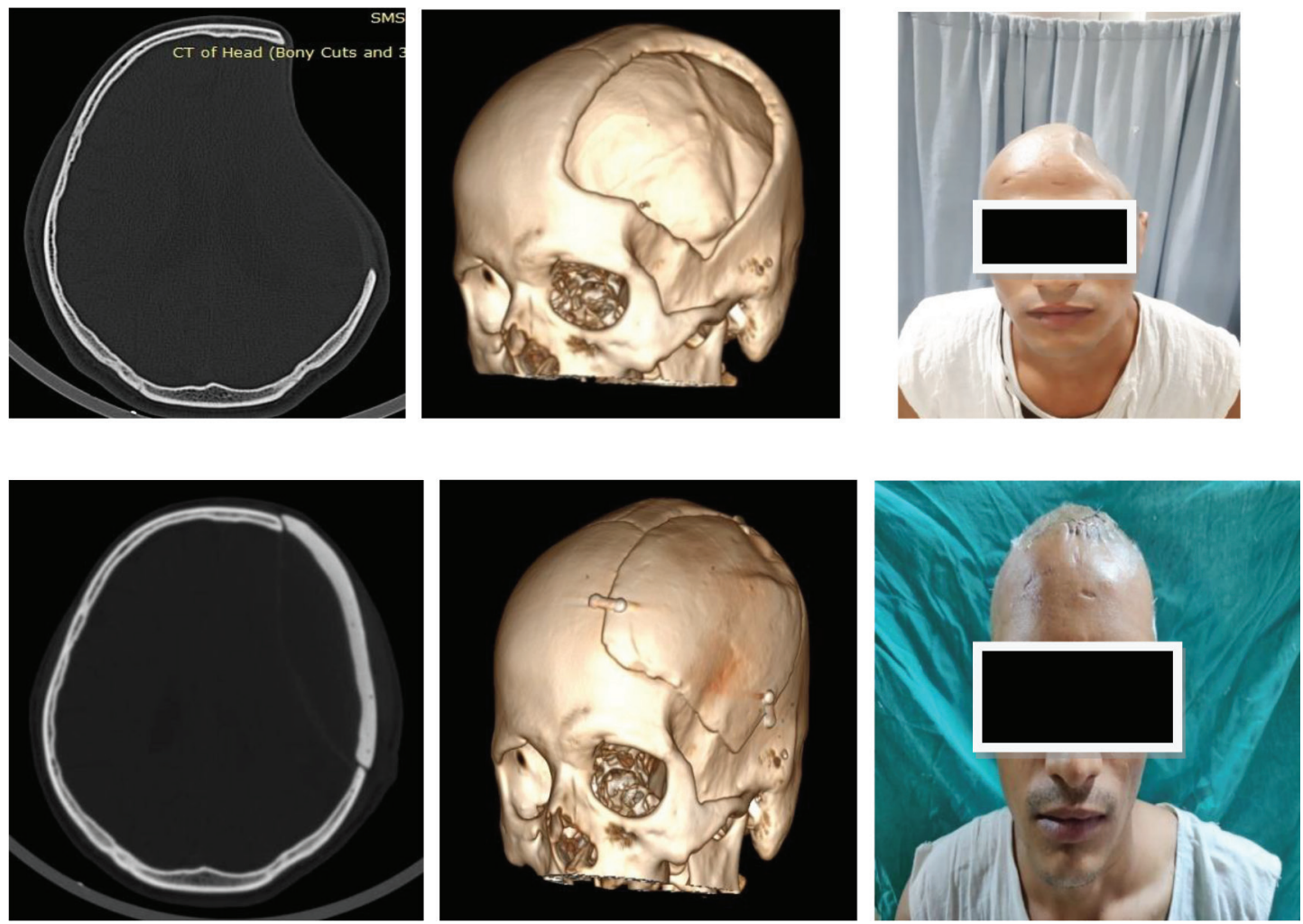

Fig. 3 First row showing preoperative images of a patient with left FTP craniectomy defect. Second row showing corresponding postoperative images with excellent restoration of margins and cranial contour.

craniofacial bones. In the late 1990s, modified cranioplasty techniques were introduced to the reconstruction of complex or extensive cranial defects, consisting of 3D stereolithography and template modeling. Laser stereolithography is accurate to less than $1 \mathrm{~mm}$, which is an improvement compared with conventional milling techniques. This technique demonstrated excellent results for the replication of complex geometric shape. In customized cranioplasty using stereolithography, the defect-bearing biomodel is utilized to mold a master implant following the creation of an impression mold of the cavity. Subsequently, a carbon-fiber reinforced polymer or acrylic implant is shaped by the mold. However, the master implant must be constructed by hand into the defect in this model. In addition, the biomodel manufacturing time for stereolithography is about twice as long as that of 3D printing technology. Recently, the development of 3D printing technology has introduced 3D medical models to generate an exact copy of patient's skull and facial bone structures..$^{20,22}$ It allows prefabricated copy models to simulate preoperative or intraoperative procedures. In the present study, we applied 3D printing technology for the prefabrication of a mold which can create an implant for the reconstruction of the cranial defect. The image of the implant was generated by a digital substraction mirror-imaging process whereby the normal side of the cranium was used as a model. We developed a 3D model by using high-resolution $(0.8-\mathrm{mm}$ cuts) spiral CT scans. The routine CT scans performed before the craniectomy were usually 5-mm thick. Consequently, the prosthesis had a stair-like surface because the 3D model was manufactured using the relatively thick spiral CT data and routine CT image may not be suitable for the creation of a precise model. In bilateral decompressive craniectomy, precise model formation may be difficult as there is no normal side of cranium to use as a mirror image. We used precraniectomy routine $\mathrm{CT}$ image data to manufacture bilateral PMMA casting model in one of our case to overcome this problem. Cranioplasty after decompressive craniectomy is performed approximately 3 months after the craniectomy, which allows sufficient time for neurological and medical recovery, but the optimal timing remains controversial. ${ }^{24,25}$ In our case, the mean time to cranioplasty was 7.4 months which can be attributed to poor compliance for second surgery. When using 3D model in cranioplasty, operation time might reduce as the molding process can be performed by the assistant during surgical exploration. In our study mean operation time was 151.6 minutes (range 130-190 minutes). Lee et al have also reported similar findings in their study. ${ }^{20}$ Numerous materials are available for reconstructive surgery of skull vault defects, but most of them are expensive. A simple plain titanium mesh can cost upto $\$ 2,000$ (US dollars), approximately. A patient-specific polyetheretherketone (PEEK) implant for craniofacial reconstruction can cost around $\$ 2,700$. The customized prostheses proposed in our study using 3D generated mold have a cost of approximately $\$ 300,6$ to 7 times cheaper than western counterparts. Infection with wound gape developed in one (3.3\%) patient. Compared with the literature, infection rate in our study was lesser. ${ }^{26-30}$ One of our patients developed frontal and parietal lobe contusion highlighting the importance of meticulous dissection of the skin flap from the dural surface so as to 
prevent injury to the underlying brain parenchyma. ${ }^{28}$ Apart from one patient $(3.3 \%$ ) we did not encounter any case with extradural hematoma formation, which was comparable to the incidence in literature. ${ }^{28,30}$ In our study, no postoperative seizures were seen against the reported incidence between 3.4 and $14.8 \%^{25,30}$

\section{Lessons Learnt}

Infection with wound gape was less in our study, which could be attributed as we take cranioplasty as first case, reduced operative time attributed to 3D printed mold, and case being operated by senior surgeon. With due course of time we started dissecting temporalis muscle to make implant fit exactly in sphenoidal aspect of defect. We were able to separate implant comfortably after applying bone wax over surface of mold. Bum-Joon et al in their study used saline to moisturize the surface to prevent adhesion. ${ }^{31}$ In two patients who were included in our study, the outer surface was uneven which was attributed to the inadequate amount of PMMA resin, so preoperative assessment of volume of resin used should be according to the volume of cranioplasty defect.

\section{Conclusion}

This technique involves a comprehensive workflow to fabricate 6 to 7 times less expensive cost than other studies. This technique can be very useful for low socioeconomic and developing countries. Considerable reduction in operation time and an accurate reconstruction of the original skull contour was achieved in our study.

\section{Conflict of Interest}

None declared.

\section{References}

1 Dumbrigue HB, Arcuri MR, LaVelle WE, Ceynar KJ. Fabrication procedure for cranial prostheses. J Prosthet Dent 1998;79(2):229-231

2 Lee C, Antonyshyn OM, Forrest CR. Cranioplasty: indications, technique, and early results of autogenous split skull cranial vault reconstruction. J Craniomaxillofac Surg 1995;23(3):133-142

3 Erdogan E, Düz B, Kocaoglu M, Izci Y, Sirin S, Timurkaynak E. The effect of cranioplasty on cerebral hemodynamics: evaluation with transcranial Doppler sonography. Neurol India 2003;51(4):479-481

4 Liang W, Xiaofeng Y, Weiguo L, et al. Cranioplasty of large cranial defect at an early stage after decompressive craniectomy performed for severe head trauma. J Craniofac Surg 2007;18(3):526-532

5 Beumer J III, Firtell DN, Curtis TA. Current concepts in cranioplasty. J Prosthet Dent 1979;42(1):67-77

6 Jordan RD, White JT, Schupper N. Technique for cranioplasty prosthesis fabrication. J Prosthet Dent 1978;40(2):230-233

7 Morales-Gómez JA, Garcia-Estrada E, Leos-Bortoni JE, et al. Cranioplasty with a low-cost customized polymethylmethacrylate implant using a desktop 3D printer. J Neurosurg 2018;130(5):1-7

8 Marchac D, Greensmith A. Long-term experience with methylmethacrylate cranioplasty in craniofacial surgery. J Plast Reconstr Aesthet Surg 2008;61(7):744-752, discussion 753
9 Roa TT, Materiales inertes. In: En Coiffman F, ed. Texto de Cirugía Plástica, Reconstructiva y Estética, Vol. 1. Barcelona, Spain: Salvat Editores; 1986

10 Golz T, Graham CR, Busch LC, Wulf J, Winder RJ. Temperature elevation during simulated polymethylmethacrylate (PMMA) cranioplasty in a cadaver model. J Clin Neurosci 2010;17(5):617-622

11 Baumeister S, Peek A, Friedman A, Levin LS, Marcus JR. Management of postneurosurgical bone flap loss caused by infection. Plast Reconstr Surg 2008;122(6):195e-208e

12 Flannery T, McConnell RS. Cranioplasty: why throw the bone flap out? Br J Neurosurg 2001;15(6):518-520

13 Gao LL, Rogers GF, Clune JE, et al. Autologous cranial particulate bone grafting reduces the frequency of osseous defects after cranial expansion. J Craniofac Surg 2010;21(2):318-322

14 Weber RS, Kearns DB, Smith RJ. Split calvarium cranioplasty. Arch Otolaryngol Head Neck Surg 1987;113(1):84-89

15 Aydin S, Kucukyuruk B, Abuzayed B, Aydin S, Sanus GZ Cranioplasty: review of materials and techniques. J Neurosci Rural Pract 2011;2(2):162-167

16 Courville CB. Cranioplasty in prehistoric times. Bull Los Angel Neuro Soc 1959;24(1):1-8

17 Durand JL, Renier D, Marchac D. The history of cranioplasty [in French]. Ann Chir Plast Esthet 1997;42(1):75-83

18 Matsuno A, Tanaka H, Iwamuro H, et al. Analyses of the factors influencing bone graft infection after delayed cranioplasty. Acta Neurochir (Wien) 2006;148(5):535-540, discussion 540

19 Eppley BL. Biomechanical testing of alloplastic PMMA cranioplasty materials. J Craniofac Surg 2005;16(1):140-143

20 Lee SC, Wu CT, Lee ST, Chen PJ. Cranioplasty using polymethyl methacrylate prostheses. J Clin Neurosci 2009;16(1):56-63

21 D'Urso PS, Earwaker WJ, Barker TM, et al. Custom cranioplasty using stereolithography and acrylic. Br J Plast Surg 2000; 53(3):200-204

22 Goh RC, Chang CN, Lin CL, Lo LJ. Customised fabricated implants after previous failed cranioplasty. J Plast Reconstr Aesthet Surg 2010;63(9):1479-1484

23 Lambrecht JT, Brix F. Individual skull model fabrication for craniofacial surgery. Cleft Palate J 1990;27(4):382-385, discussion 386-387

24 Piedra MP, Ragel BT, Dogan A, Coppa ND, Delashaw JB. Timing of cranioplasty after decompressive craniectomy for ischemic or hemorrhagic stroke. J Neurosurg 2013;118(1):109-114

25 Walcott BP, Kwon CS, Sheth SA, et al. Predictors of cranioplasty complications in stroke and trauma patients. J Neurosurg 2013;118(4):757-762

26 Hong KS, Kang SH, Lee JB, Chung YG, Lee HK, Chung HS. Cranioplasty with the porous polyethylene implant (Medpor) for large cranial defect. J Korean Neurosurg Soc 2005;38: 96-101

27 Chang V, Hartzfeld P, Langlois M, Mahmood A, Seyfried D. Outcomes of cranial repair after craniectomy. J Neurosurg 2010;112(5):1120-1124

28 Gooch MR, Gin GE, Kenning TJ, German JW. Complications of cranioplasty following decompressive craniectomy: analysis of 62 cases. Neurosurg Focus 2009;26(6):E9

29 Klinger DR, Madden C, Beshay J, White J, Gambrell K, Rickert K. Autologous and acrylic cranioplasty: a review of 10 years and 258 cases. World Neurosurg 2014;82(3-4):e525-e530

30 Lee L, Ker J, Quah BL, Chou N, Choy D, Yeo TT. A retrospective analysis and review of an institution's experience with the complications of cranioplasty. Br J Neurosurg 2013;27(5):629-635

31 Kim BJ, Hong KS, Park KJ, Park DH, Chung YG, Kang SH. Customized cranioplasty implants using three-dimensional printers and polymethyl-methacrylate casting. J Korean Neurosurg Soc 2012;52(6):541-546 